\title{
Changing patterns of teenage pregnancy: population based study of small areas
}

\author{
Alice McLeod
}

\begin{abstract}
Objectives To measure the impact of socioeconomic deprivation on rates of teenage pregnancy and the extent of local variation in pregnancy rates in Scotland, and to examine how both have changed over time.

Design Population study using routine data from hospital records, aggregated for small areas. Subjects Female teenagers resident in Scotland who were treated for pregnancy in an NHS hospital in either 1981-5 (62 338 teenagers) or 1991-5 (48 514) and who were aged 13-19 at the time of conception. Main outcome measures Pregnancy rates per 1000 in age group and the proportions of pregnancies resulting in a maternity (live birth or stillbirth) in teenagers aged 13-15, 16-17, and 18-19.
\end{abstract}

Results From the 1980 s to the 1990 s pregnancy rates increased differentially according to levels of local deprivation, as measured by the Carstairs index. Among teenagers aged less than 18 the annual pregnancy rate increased in the most deprived areas (from 7.0 to 12.5 pregnancies per 1000 13-15 year olds and from 67.6 to 84.6 per 100016 - 17 year olds), but there was no change, on average, among teenagers in the most affluent areas (3.8 per 1000 13-15 year olds and 28.9 per $100016-17$ year olds). Among 18-19 year olds the pregnancy rate decreased in the most affluent areas (from 60.0 to 46.3 per 1000 ) and increased in the most deprived areas (from 112.4 to 116.0 per 1000 ). The amount of local variation explained by deprivation more than doubled from the 1980 s to the $1990 \mathrm{~s}$. The proportion of pregnancies resulting in a maternity was positively associated with level of deprivation, but the effect remained similar over time.

Conclusion From the 1980s to the 1990s the difference in rates of teenage pregnancy between more affluent and more deprived areas widened. This has implications for allocating resources to achieve government targets and points to important social processes behind the general increase in the number of teenage pregnancies in Scotland.

\section{Introduction}

Consistently high rates of teenage pregnancy in the United Kingdom prompted governments to set targets for reduction at both the start and the end of the 1990s. ${ }^{12}$ In England and Wales the most recent target is a reduction of $50 \%$ in the pregnancy rate in teenagers aged less than 18 by 2010 ; this is to be achieved by targeting male teenagers, improving sex education, and improving young people's access to contraceptive services. ${ }^{2}$ In Scotland the target is a reduction of $20 \%$ in the pregnancy rate in 13-15 year olds by $2010 .{ }^{3}$ One aim of the recently launched "Healthy Respect" project is to develop the best practices to help meet this target (Scottish Executive press release, November 2000).
One suggested cause of the high pregnancy rate in the United Kingdom, compared with the rest of Europe, is that fewer British teenagers use contraception. $^{2}$ It is unclear whether this is due to difficulty in accessing contraception; in the United Kingdom contraception may be obtained from general practitioners and family planning clinics, and condoms are widely available in shops and from vending machines. Indeed, the wide range of contraceptive services makes it difficult to assess their comparative effectiveness. In England reduced rates of teenage pregnancy have been found to be associated with proximity to youth family planning clinics. ${ }^{4}$ Recent research found that most teenagers who became pregnant had consulted their general practitioner for contraceptive services in the year preceding the pregnancy. ${ }^{5}$ Rather than obtaining a direct measure of service provision, which in practice is determined by perceived need, we might consider the extent of systematic variation in pregnancy rates between local areas as an indicator of access to contraceptive services.

Local variation in rates of teenage pregnancy is complex, and differential access to contraceptive services may be only one component. What is well established is the association in the United Kingdom between socioeconomic deprivation and teenage pregnancies. The reasons for this association are manifold: in addition to cultural differences in attitudes to early motherhood, sexual risk taking-defined as earlier or unprotected sexual activity-is influenced by employment and educational aspirations.. ${ }^{26}$ Hence abstinence or use of contraceptives is more common among teenagers for whom becoming pregnant results in a greater loss of opportunities. Differences in teenagers' aspirations or perceived opportunities according to level of socioeconomic deprivation will therefore be reflected in pregnancy rates.

Given the current concerns about teenage pregnancy in the United Kingdom, I used national data to quantify the extent of small area variation in pregnancy rates and outcomes in Scotland and how much of this variation can be explained by socioeconomic deprivation. I analysed data for both the 1980 s and 1990s to consider the changes between these two periods within the context of the attainment of government targets by 2010 .

\section{Methods}

Data

Data on the numbers and outcomes of pregnancies were obtained from the Information and Statistics Division of the Common Services Agency in Scotland. Data on conceptions were obtained from SMR1 and SMR2 (Scottish morbidity records); SMR1 records all inpatient and day case episodes in acute specialties, excluding obstetrics, and SMR2 records all episodes in obstetrics. Data on births were derived from SMR2,
MRC Social and
Public Health
Sciences Unit,
University of
Glasgow, Glasgow
G12 8RZ
Alice McLeod
research associate
a.mcleod@
psychology.bbk.
ac.uk
BMJ 2001:323:199-203 
and data on pregnancies resulting in abortion or miscarriage were derived from both sets of records. The methods used to extract records and classify pregnancy outcomes in this study were the same as those used by the Information and Statistics Division for the reporting of birth statistics in Scotland.?

The Information and Statistics Division provided information on the age of each teenager at the time of conception, postcode sector of residence, marital status, and pregnancy outcome. Pregnancy outcome was classified as maternity (live births and stillbirths), therapeutic abortion, or miscarriage and other (for example, abortion with complications). Records were grouped into postcode sectors, and population estimates were abstracted from the 1981 and 1991 censuses. Two small area characteristics were used from each census: socioeconomic deprivation was measured by scores on the Carstairs index, grouped by quartile into "most affluent," "mid-affluent," "middeprived," and "most deprived," and areas were classed as urban or rural on the basis of the proportion of the population resident in urban locations with a population $>10000 .^{8}$

\section{Statistical methods}

The two outcomes were pregnancy rate, a proxy for conception rate, and pregnancy outcome. Both outcomes were measured at the level of small area and were analysed for each of three age groups, 13-15, 16-17, and 18-19 years, based on the maternal age at conception. To assess change over time I analysed data for two periods, 1981-5 (889 postcode sectors) and 1991-5 (895 postcode sectors); data were aggregated over five years to increase statistical power.

Pregnancy rates in 16-17 and 18-19 year olds were expressed as the ratio of observed to expected pregnancies, in order to standardise for marital status. The expected number of pregnancies was derived by applying national rates in married and unmarried teenagers to local married and unmarried populations, then adding the results to obtain a total. The expected number of pregnancies in 13-15 year olds in each area was derived from the total national rate. Pregnancy outcome was expressed as the proportion of conceptions resulting in a maternity; outcomes classed as miscarriage and other were excluded. This proportion was calculated separately for married and unmarried teenagers in each age group. I considered marital status to be an important indicator of the cultural background of young women, although in some cases conception would have preceded marriage.

Multilevel Poisson regression was used to model pregnancy rates and multilevel logistic regression to model pregnancy outcome. ${ }^{4}$ This approach provided estimates of the effect of small area characteristics as well as estimates of systematic variation in teenage pregnancies between small areas in Scotland. Estimates of systematic variation were expressed as the ratio of the 95 th to the 5th centile in the distribution of small area effects. ${ }^{9}$

One health board did not record the postcode sector of residence on the majority of hospital records throughout the 1980s; data from this health board were excluded from the 1981-5 analyses reported in tables 2 and 3. To assess the effect of this exclusion on longitudinal comparisons, I redid the 1991-5 analyses with the data for the same health board excluded; this exclusion made little difference to the results.

\section{Results}

\section{National statistics}

The female teenage population in Scotland decreased notably from 1981 to 1991: the number of 13-15 and 16-17 year olds decreased by about $30 \%$ and that of 18 -19 year olds by just under 20\% (table 1). From the early 1980 s to the early 1990 s the pregnancy rate increased among teenagers aged less than 18 and decreased among 18-19 year olds. In 1981-5 just under half the pregnancies in 18-19 year olds were to teenagers who were married, compared with only $14 \%$ in 1991-5 - that is, there was a considerable increase in the pregnancy rate among unmarried 18-19 year olds. The proportion of maternities was unchanged among 13-15 year olds but decreased among teenagers aged 16 or over. Although the proportion of teenagers marrying decreased from 1981 to 1991, the effect of marital status remained strong, with the chance of both pregnancy and maternity being much greater among married teenagers. So few married teenagers had an abortion that, in order to standardise for marital status, I excluded this group from analyses of pregnancy outcome.

Changes in the impact of socioeconomic deprivation The results showed a clear gradient: as level of local deprivation increased, both pregnancy rate and the proportion of maternities increased, for all age groups and in both periods (table 2). From the 1980s to the

Table 1 Pregnancies and maternities (live births or stillbirths) in teenagers in Scotland in 1981-5 and 1991-5, according to marital status

\begin{tabular}{|c|c|c|c|c|c|c|}
\hline & \multicolumn{2}{|c|}{ Age 13-15 } & \multicolumn{2}{|c|}{ Age 16-17 } & \multicolumn{2}{|c|}{ Age 18-19 } \\
\hline & 1981-5 & 1991-5 & 1981-5 & 1991-5 & 1981-5 & 1991-5 \\
\hline Population in census year (\% married) & $128338(0)$ & $87968(0)$ & $89400(1.6)$ & $63098(0.5)$ & 83481 (11.3) & $67995(3.1)$ \\
\hline No of pregnancies: & 3845 & 3972 & 21596 & 17138 & 36897 & 27404 \\
\hline Unmarried & 3845 & 3972 & 15646 & 16257 & 18556 & 23650 \\
\hline Married & 0 & 0 & 5950 & 881 & 18341 & 3754 \\
\hline Annual pregnancy rate (per 1000 in age group): & 6 & 9 & 48 & 54 & 88 & 81 \\
\hline Unmarried & 6 & 9 & 36 & 52 & 50 & 71 \\
\hline Married & 0 & 0 & 812 & 537 & 389 & 347 \\
\hline No of maternities (\% of pregnancies ${ }^{*}$ ): & $1882(51)$ & $1910(51)$ & $14127(70)$ & $10417(66)$ & $26950(79)$ & $17421(70)$ \\
\hline Unmarried & $1656(48)$ & $1877(51)$ & $8518(59)$ & $9626(65)$ & $10317(61)$ & $14126(65)$ \\
\hline Married & $226(99 \dagger)$ & $33(100 \dagger)$ & $5609(98)$ & $791(95)$ & $16633(97)$ & $3295(95)$ \\
\hline
\end{tabular}

*Excluding miscarriages and other outcomes (for example, abortion with complications).

tIncludes teenagers who were aged 15 at the time of conception but were 16 and married by the end of the pregnancy (230 teenagers were in this category in 1981-5 and 35 in 1991-5). 
Table 2 Pregnancies and maternities (live births or stillbirths) in teenagers in Scotland, according to level of local deprivation and whether area is urban or rural

\begin{tabular}{|c|c|c|c|c|c|c|c|c|}
\hline \multirow[b]{3}{*}{ Small area covariate } & \multicolumn{4}{|c|}{ Pregnancies } & \multicolumn{4}{|c|}{ Maternities } \\
\hline & \multicolumn{2}{|c|}{$\begin{array}{c}\text { Average annual rate (per } 1000 \\
\text { in age group) }\end{array}$} & \multicolumn{2}{|c|}{$\begin{array}{l}\text { Adjusted factor change* } \\
\qquad(95 \% \mathrm{CI})\end{array}$} & \multicolumn{2}{|c|}{$\begin{array}{l}\text { Average annual } \% \text { of } \\
\text { pregnancies }\end{array}$} & \multicolumn{2}{|c|}{$\begin{array}{l}\text { Adjusted odds ratio* } \\
\qquad(95 \% \mathrm{Cl})\end{array}$} \\
\hline & $1981-5 \dagger$ & $1991-5$ & $1981-5 \dagger$ & $1991-5$ & $1981-5 \dagger$ & $1991-5$ & $1981-5 \dagger \ddagger$ & 1991-5ł \\
\hline \multicolumn{9}{|l|}{ Age 13-15 } \\
\hline \multicolumn{9}{|l|}{ Carstairs scores§: } \\
\hline Most affluent & 3.8 & 3.9 & 1 & 1 & 32.5 & 32.8 & 1 & 1 \\
\hline Mid-affluent & 4.7 & 7.4 & 1.2 (1.0 to 1.5$)$ & 1.8 (1.6 to 2.1$)$ & 41.6 & 41.6 & 1.6 (1.2 to 2.2$)$ & 1.7 (1.3 to 2.2$)$ \\
\hline Mid-deprived & 6.1 & 9.1 & 1.6 (1.3 to 1.8$)$ & 2.3 (2.0 to 2.6$)$ & 53.6 & 50.4 & 2.1 (1.6 to 2.8 ) & 2.0 (1.5 to 2.5$)$ \\
\hline Most deprived & 7.0 & 12.5 & 1.9 (1.6 to 2.2$)$ & $3.0(2.6$ to 3.4$)$ & 60.1 & 59.4 & $3.1(2.3$ to 4.1$)$ & 3.0 (2.3 to 3.8$)$ \\
\hline \multicolumn{9}{|l|}{ Location: } \\
\hline Rural & 4.9 & 6.0 & 1 & 1 & 42.6 & 43.1 & 1 & 1 \\
\hline Urban & 5.7 & 9.7 & $0.9(0.8$ to 1.0$)$ & $1.1(1.0$ to 1.2$)$ & 50.9 & 49.0 & $1.1(0.9$ to 1.4$)$ & 1.0 (0.8 to 1.2$)$ \\
\hline \multicolumn{9}{|l|}{ Age 16-17 } \\
\hline \multicolumn{9}{|l|}{ Carstairs scores§: } \\
\hline Most affluent & 28.9 & 28.1 & 1 & 1 & 45.4 & 40.2 & 1 & 1 \\
\hline Mid-affluent & 40.7 & 38.9 & $1.3(1.2$ to 1.5$)$ & $1.6(1.4$ to 1.7$)$ & 56.6 & 57.0 & $1.6(1.3$ to 1.9$)$ & 1.9 (1.6 to 2.2$)$ \\
\hline Mid-deprived & 46.3 & 58.7 & $1.6(1.4$ to 1.8$)$ & $2.2(2.0$ to 2.4$)$ & 66.5 & 63.6 & $2.4(2.1$ to 2.9$)$ & 2.6 (2.3 to 3.1$)$ \\
\hline Most deprived & 67.6 & 84.6 & 1.9 (1.8 to 2.1$)$ & 3.0 (2.7 to 3.3$)$ & 76.9 & 71.6 & 4.6 (3.9 to 5.4$)$ & 4.1 (3.5 to 4.7 ) \\
\hline \multicolumn{9}{|l|}{ Location: } \\
\hline Rural & 39.0 & 39.2 & 1 & 1 & 58.6 & 55.3 & 1 & 1 \\
\hline Urban & 50.8 & 61.9 & $1.0(0.9$ to 1.1$)$ & $1.1(1.0$ to 1.2$)$ & 63.5 & 60.4 & $1.0(0.8$ to 1.1$)$ & $1.0(0.9$ to 1.1$)$ \\
\hline \multicolumn{9}{|l|}{ Age 18-19 } \\
\hline \multicolumn{9}{|l|}{ Carstairs scores§: } \\
\hline Most affluent & 60.0 & 46.3 & 1 & 1 & 60.5 & 50.9 & 1 & 1 \\
\hline Mid-affluent & 79.3 & 64.2 & 1.2 (1.1 to 1.3$)$ & 1.4 (1.3 to 1.5) & 73.0 & 64.5 & 1.9 (1.6 to 2.2$)$ & 2.0 (1.7 to 2.3$)$ \\
\hline Mid-deprived & 88.1 & 91.4 & $1.4(1.3$ to 1.5$)$ & 1.8 (1.7 to 2.0 ) & 77.9 & 70.0 & 2.8 (2.4 to 3.3 ) & 2.9 (2.5 to 3.4$)$ \\
\hline Most deprived & 112.4 & 116.0 & $1.7(1.6$ to 1.8$)$ & $2.4(2.2$ to 2.6$)$ & 81.7 & 73.4 & 5.3 (4.5 to 6.3$)$ & 4.0 (3.5 to 4.7$)$ \\
\hline \multicolumn{9}{|l|}{ Location: } \\
\hline Rural & 83.9 & 67.6 & 1 & 1 & 76.4 & 67.3 & 1 & 1 \\
\hline Urban & 86.1 & 87.5 & $0.9(0.8$ to 1.0$)$ & $1.1(1.0$ to 1.2$)$ & 71.6 & 63.4 & 0.7 (0.6 to 0.8$)$ & $0.8(0.7$ to 0.9$)$ \\
\hline
\end{tabular}

${ }^{*}$ Adjusted for marital status, level of local deprivation, and urban or rural location.

†Excluding one health board covering 48 postcode sectors. Population size of this area in 1981 (No of pregnancies/No of maternities in 1981-5): age 13-15=8246 (328/132); 16-17=5638 (1596/1008); 18-19=5377 (2675/1964).

$\neq$ Results relate only to unmarried teenagers.

$\S S$ cores divided into four groups by quartile.

1990 s the average pregnancy rate among teenagers aged less than 18 was relatively constant in the most affluent areas but increased in more deprived areas. The average pregnancy rate among 18-19 year olds decreased in the more affluent areas and increased slightly in deprived areas. The national decrease in maternities was, however, generally reflected in each deprivation category. Not adjusting for marital status had the effect of increasing deprivation differentials, because marriage was more prevalent in areas of higher deprivation; this was most noticeable in the 1980s, when marriage was more common.

\section{Differential effects of deprivation in urban and rural areas}

The observed pregnancy rates and the probability of a maternity were higher in urban areas; however, adjustment for deprivation largely removed this effect (table 2). Indeed, after adjustment for deprivation and marital status, maternities were significantly less likely among 18-19 year olds living in urban areas.

It is important to consider the effects of deprivation separately for urban and rural areas. ${ }^{4}$ This was done by adding interaction terms between these two factors to the models reported in table 2 . In both periods the effect of deprivation on the pregnancy rate was significantly greater in urban than in rural areas-in 1991-5, for example, $16-17$ year olds in the most deprived rural areas were 2.3 times $(95 \%$ confidence interval 1.9 to 2.8) more likely to become pregnant than those in affluent rural areas, and the equivalent risk in the most deprived urban areas, compared with affluent urban areas, was 3.1 (2.5 to 3.9). The differential effects of deprivation with regard to pregnancy outcome were less consistent and not significant. For both outcomes, adjustment for the differential effects of deprivation in urban and rural areas explained little more systematic variation than that explained by deprivation alone.

\section{Changes in small area variation}

Without adjustment for the effects of deprivation, small area variation increased in pregnancy rates but decreased in the proportion of maternities from the 1980 s to the 1990 s (table 3). Furthermore, whereas the degree of small area variation in pregnancy rates was greater in younger teenagers, the opposite was true for maternities. From the 1980 s to the 1990 s the amount of local variation in pregnancy rates explained by deprivation trebled in 13-15 year olds and doubled in the two older age groups. The amount of local variation in pregnancy outcome explained by deprivation more than doubled in 13-15 year olds.

To illustrate the extent to which deprivation accounted for local variation in the 1990s, table 4 shows the predicted reduction in numbers of pregnancies for two hypothetical situations. If it is assumed that the rates in all areas were, on average, the same as those in the most affluent areas, but that the same level of unexplained variation remained, the number of pregnancies in teenagers under 18 would be halved. If 
Table 3 Systematic variation between small areas in Scotland in rates of pregnancy and proportions of maternities (live births and stillbirths)

\begin{tabular}{|c|c|c|c|c|}
\hline \multirow[b]{2}{*}{ Outcome by age group } & \multicolumn{2}{|c|}{ Ratio of 95 th to 5 th centile in small area variation* $(95 \% \mathrm{Cl})$} & \multicolumn{2}{|c|}{$\%$ of small area variation explained by deprivation $(95 \% \mathrm{Cl})$} \\
\hline & $1981-5$ & $1991-5$ & $1981-5$ & 1991-5 \\
\hline \multicolumn{5}{|l|}{ Pregnancies: } \\
\hline $13-15$ & 5.5 (4.6 to 6.5$)$ & $6.2(5.3$ to 7.2$)$ & 17 (0 to 34$)$ & 53 (41 to 64$)$ \\
\hline 16-17 & $4.3(3.9$ to 4.7$)$ & $6.0(5.3$ to 6.6$)$ & $30(20$ to 40$)$ & 61 (55 to 67$)$ \\
\hline 18-19 & $3.2(3.0$ to 3.5$)$ & $4.6(4.2$ to 5.0$)$ & 29 (19 to 39$)$ & 58 (52 to 64) \\
\hline \multicolumn{5}{|l|}{ Maternities: } \\
\hline $13-15$ & 8.4 (5.7 to 11.5$)$ & $4.0(2.7$ to 5.5$)$ & 38 (10 to 66$)$ & 79 (40 to 100$)$ \\
\hline $16-17$ & 11.0 (9.0 to 13.2$)$ & $8.0(6.7$ to 9.5$)$ & 60 (51 to 69$)$ & 68 (59 to 77$)$ \\
\hline $18-19$ & $13.0(10.7$ to 15.7$)$ & 10.4 (8.7 to 12.2$)$ & 53 (44 to 62 ) & 46 (37 to 55$)$ \\
\hline
\end{tabular}

* Ratios are not comparable between the two outcomes: pregnancy rates are based on ratios of observed and expected pregnancies, and maternities on odds ratios.

the effects of deprivation are retained and the unexplained systematic variation removed, this reduction would be less than $10 \%$.

\section{Discussion}

Pregnancy rates among teenagers in Scotland increased differentially from the 1980 s to the 1990 s, according to the level of local deprivation. Over and above the effects of local deprivation, and whether the area was urban or rural (which had little effect on pregnancy rates and outcomes), small area variation existed and may indicate different levels of provision of contraceptive services. However, eradicating the unexplained local variation would make little difference in terms of reducing numbers of pregnancies, compared with reducing the effects of deprivation, such that the patterns of sexual activity and access to contraception among young women in the most affluent areas would be seen throughout Scotland.

The pregnancy rates reported here can only approximate the underlying conception rates in the teenage population. Not all conceptions will result in a hospital admission; an early spontaneous abortion may go unrecognised or be managed by a general practitioner. Also, rates were derived from NHS records; it is possible that bias may arise from proportionately more teenagers in affluent areas being treated in the private sector. It is not possible to quantify this bias with the available data; however, notifications to the chief medical officer of abortions among all Scottish residents showed that the proportion carried out in Scottish NHS hospitals increased during the study period $(89.2 \%$ in 1983 to $95 \%$ in 1993$) .{ }^{11}$ Finally, the analyses assumed that cases were independent, when it is likely that some teenagers became pregnant more than once. At present the SMR1 records are linked, but without SMR2 they form an incomplete database to estimate repeat pregnancies in Scotland. It is important to quantify repeat pregnancies: the risk of pregnancy is known to increase among

Table 4 Predicted reduction in numbers (percentages) $\dagger$ of pregnancies in teenagers in Scotland, based on estimated effects of deprivation and unexplained small area variation in 1991-5

\begin{tabular}{lcc} 
Age group & $\begin{array}{c}\text { Deprivation effects removed } \\
\text { area variation maintained }\end{array}$ & $\begin{array}{c}\text { Deprivation effects maintained + small area } \\
\text { variation removed }\end{array}$ \\
\hline $13-15$ & $2132(54)$ & $295(7.4)$ \\
\hline $16-17$ & $8888(52)$ & $934(5.4)$ \\
\hline $18-19$ & $12003(44)$ & $1289(4.7)$ \\
\hline
\end{tabular}

*Assuming that pregnancy rates in all areas are the same as those in the most affluent areas. tExpressed as a percentage of total pregnancies in 1991-5, as reported in table 1.

\section{What is already known on this topic}

Rates of teenage pregnancy are considerably higher in the United Kingdom than in other western European countries

In the United Kingdom rates of teenage pregnancy are known to be higher in areas of greater socioeconomic deprivation, although local variation may also reflect differential access to family planning services

\section{What this study adds}

From 1981-5 to 1991-5 rates of teenage pregnancy in Scotland increased more rapidly in areas of greater socioeconomic deprivation

In the 1990s socioeconomic deprivation explained more than $50 \%$ of local variation in rates of teenage pregnancy, more than double the amount explained by it in the 1980 s

teenagers who have already conceived; therefore the benefits of a reduced risk in younger teens would also be seen in the pregnancy rate among older teens. ${ }^{12}$

Although the usual caveats regarding ecological associations apply to the results of this study, the increased effect of socioeconomic deprivation in the 1990s does have implications for allocating resources to achieve targets in reducing pregnancy rates. In Scotland family planning services are coordinated at the level of health board, and some boards have a much higher concentration of deprived localities. However, improved access to contraception does not ensure that it will be used. $^{13}$ Sex education may play an important role in helping to reduce unwanted teenage pregnancies, but the increased impact of deprivation in the 1990s indicates other social processes behind the patterns of change. In particular, it is important to establish whether increased inequality in rates of teenage pregnancy in the early 1990s reflect increased inequality in educational and employment opportunities at that time.

I am grateful to M Hollinsworth, B Cant, and J Chalmers at the Information and Statistics Division for their help in supplying the data and to G Raab and colleagues at the Social and Public Health Sciences Unit for their comments.

Funding: This research was supported by the Medical Research Council and the Chief Scientist Office of the Scottish Executive Health Department. Opinions and conclusions expressed in this paper are not necessarily those of either organisation.

Competing interests: None declared. 
Department of Health. Health of the nation. London: HMSO, 1992.

Social Exclusion Unit. Teenage pregnancy. London: Stationery Office, 1999

Scottish Office. Towards a healthier Scotland. Edinburgh: Stationery Office, 1999

4 Diamond I, Clements S, Stone N, Ingham R. Spatial variation in teenage conceptions in south and west England. J R Stat Soc Ser A 1999;162:27389.

5 Churchill D, Allen J, Pringle M, Hippisley-Cox J, Ebdon D, Macpherson $\mathrm{M}$, et al. Consultation patterns and provision of contraception in general practice before teenage pregnancy: case-control study. BMJ 2000;321:486-9.

6 Smith T. Influence of socioeconomic factors on attaining targets for reducing teenage pregnancies. BMJ 1993;306:1232-5.

7 ISD. Teenage pregnancy in Scotland: a fifteen year review, 1983-97. Edinburgh: Common Services Agency for the Scottish Health Service, Information and Statistics Division, 1998 .
8 Carstairs V, Morris R. Deprivation and health in Scotland. Aberdeen: Aberdeen University Press, 1991.

9 Coory M, Gibberd R. New measures for reporting the magnitude of small-area variation in rates. Stat Med 1998;17:2625-34

10 Information and Statistics Division. Scottish health statistics 1984. Edinburgh: HMSO, 1984.

11 Information and Statistics Division. Scottish health statistics 1995. Edinburgh: HMSO, 1995.

12 Rigsby D, Macones G, Driscoll D. Risk factors for rapid repeat pregnancy among adolescent mothers: a review of the literature. J Pediatr Adoles Gynecol 1998;11:115-26.

13 Stevens-Simon C, Kelly L, Singer D, Cox A, DuRant R. Why pregnan adolescents say they did not use contraceptives prior to conception. Adolesc Health 1996; 19:48-55.

(Accepted 10 May 2001)

\section{"They're doing people a service"-qualitative study of smoking, smuggling, and social deprivation}

Susan Wiltshire, Angus Bancroft, Amanda Amos, Odette Parry

\begin{abstract}
Objectives To examine the behaviour and attitudes related to smoking and contraband tobacco products among smokers in two socially deprived areas. Design Cross sectional study with qualitative semistructured interviews, augmented by smokers' day grid.

Setting Two areas of socioeconomic deprivation in Edinburgh.

Participants 50 male and 50 female smokers aged 25-40 years randomly selected from general practitioners' lists from two health centres, each located in an area of deprivation.

Results Most smokers wanted to quit but felt unable to because of the importance of smoking in their daily routine and their addiction to nicotine. Strategies for maintaining consumption levels in the face of increasing cigarette prices and low income included purchasing contraband cigarettes and tobacco. Vendors were contacted through social networks, family, and friends as well as common knowledge of people and places, particularly pubs where contraband was available. Most users of contraband considered that smugglers were providing a valuable service. Purchasing contraband tobacco was viewed as rational in the face of material hardship. Many smokers criticised the government for its high tobacco taxation and the lack of local services to help them to stop smoking.

Conclusions Smokers in deprived areas perceive a lack of support to help them to stop smoking. Cigarette and tobacco smuggling is therefore viewed positively by low income smokers as a way of dealing with the increasing cost of cigarettes. Smokers in areas of deprivation may thus show little support for tackling smuggling until more action is taken to deal with the material and personal factors that make it difficult for them to quit.
\end{abstract}

\section{Introduction}

Smoking is strongly associated with social disadvantage and is an important contributor to inequalities in health. ${ }^{1-3}$ The greater an individual's level of disadvantage (as measured, for example, by occupation, income, education, housing tenure) the more likely they are to start smoking and the less likely they are to stop. ${ }^{45}$ The government's white papers on tobacco and public health have identified reduction in smoking among low income groups as a priority and a key element of its strategy for tackling health inequalities. ${ }^{2}{ }^{67}$ Cessation services are being targeted at low income smokers and those who live in areas of deprivation. However, there is increasing concern that the impact of these services and the government's tobacco control strategy may be being undermined by the increasing availability of cheap, smuggled cigarettes and tobacco. ${ }^{8}$

The 1990s saw a massive increase in the smuggling of tobacco and cigarettes into the United Kingdom. It is estimated that currently a quarter to a third of cigarettes smoked in the United Kingdom, worth $£ 2500$ million in lost revenue during 1999, are smuggled or contraband. ${ }^{9}$ There is clear evidence that tobacco companies are complicit in smuggling. ${ }^{8-11}$ Tobacco companies use concerns about smuggling, and the resulting lost tax revenue, to exert political pressure on the government to lower tobacco taxes. Evidence from other countries shows that lowering taxes neither decreases smuggling nor reduces overall tobacco consumption. ${ }^{10}$

However, we know little about how smokers in areas of deprivation view the issue of smuggled or contraband cigarettes and tobacco, how this relates to their own smoking behaviour, and the implications for policies and action on this issue. In this paper, which draws on a wider study of smoking in areas of deprivation, we have focused on the strategies that smokers living in such areas use to deal with the financial costs of smoking. Specifically, we considered the role of cigarette and tobacco smuggling: sources, availability, respondents' rationale for purchasing contraband, and the impact of cheaper tobacco products on smoking behaviour.

\section{Methods}

Participants and setting-We used data from a two year qualitative study of smokers living in two areas of Edin-
Public Health

Sciences,

Department of

Community Health

Sciences, University

of Edinburgh

Medical School,

Edinburgh

EH8 9AG

Susan Wiltshire

research fellow

Angus Bancroft

lecturer

Amanda Amos

senior lecturer

Research Unit in

Health, Behaviour

and Change,

Department of

Community Health

Sciences, University

of Edinburgh

Medical School

Odette Parry

senior research fellow

Correspondence to:

A Amos

amanda.amos@

ed.ac.uk

BMJ 2001;323:203-7 